\title{
Dietary methionine availability affects the main factors involved in muscle protein turnover in rainbow trout (Oncorhynchus mykiss)
}

\author{
Ikram Belghit, Sandrine Skiba-Cassy, Inge Geurden, Karine Dias, Anne Surget, Sadasivam Kaushik, \\ Stéphane Panserat and Iban Seiliez*
}

INRA, UR1067 Nutrition Métabolisme Aquaculture, F-64310 St-Pée-sur-Nivelle, France

(Submitted 15 January 2014 - Final revision received 23 April 2014 - Accepted 30 April 2014 - First published online 30 May 2014)

\section{Abstract}

Methionine is a limiting essential amino acid in most plant-based ingredients of fish feed. In the present study, we aimed to determine the effect of dietary methionine concentrations on several main factors involved in the regulation of mRNA translation and the two major proteolytic pathways (ubiquitin-proteasome and autophagy-lysosomal) in the white muscle of rainbow trout (Oncorhynchus mykiss), The fish were fed for 6 weeks one of the three isonitrogenous diets providing three different methionine concentrations (deficient (DEF), adequate (ADQ) and excess (EXC)). At the end of the experiment, the fish fed the DEF diet had a significantly lower body weight and feed efficiency compared with those fed the EXC and ADQ diets. This reduction in the growth of fish fed the DEF diet was accompanied by a decrease in the activation of the translation initiation factors ribosomal protein $\mathrm{S} 6$ and eIF $2 \alpha$. The levels of the main autophagy-related markers (LC3-II and beclin 1) as well as the expression of several autophagy genes (atg4b, atg12l, Uvrag, SQSTM1, Mul1 and Bnip3) were higher in the white muscle of fish fed the DEF diet. Similarly, the mRNA levels of several proteasome-related genes (Fbx32, MuRF2, MuRF3, ZNF216 and Trim32) were significantly up-regulated by methionine limitation. Together, these results extend our understanding of mechanisms regulating the reduction of muscle growth induced by dietary methionine deficiency, providing valuable information on the biomarkers of the effects of low-fishmeal diets.

Key words: Fish: Dietary methionine: Muscle growth: Proteolysis: Protein synthesis

Global seafood consumption, currently estimated to be 100 million tonnes, is expected to increase by another 65 million tonnes by the year 2030. Aquaculture already makes a significant contribution to this seafood supply, and this is growing at an annual rate close to $6 \%{ }^{(1)}$. Most farmed teleost fish are adapted to use amino acids as the preferred energy source over carbohydrates and thus require high levels of dietary proteins $(300-600 \mathrm{~g} / \mathrm{kg})^{(2)}$, with fishmeal being the major protein source in aquaculture. The sustainability of this practice, which requires large inputs of wild fish for feed preparation, has been questioned $^{(3)}$. Thus, the replacement of fishmeal as the major protein source with proteins of plant origin is a major objective for sustainable aquaculture in the future. Progress has been made on the replacement of fishmeal with a number of alternative protein sources of plant origin (oil seeds, cereal proteins and pulses) ${ }^{(4-7)}$. However, the replacement of fishmeal with plant proteins is often limited by methionine concentrations. In this context, supplementation of plant-based diets with synthetic methionine has been shown to optimise the nutritional value of these diets containing alternative proteins, with dietary methionine having a significant effect on growth performance and protein deposition in different fish species ${ }^{(8-11)}$. Given that muscle protein accretion is the major aim of aquaculture, the optimisation of dietary methionine supply requires precise knowledge of the role of this sulphur amino acid, especially in the muscle.

For optimising methionine nutrition, the different roles of this amino acid need to be considered. Methionine is an indispensable amino acid for the normal growth of most animals. This sulphur amino acid is a component of tissue proteins and therefore serves as a building block for protein synthesis. Decreased growth in chicks or mammals fed methionine-free diets has thus been reported to be primarily caused by lower rates of whole-body protein synthesis associated with lower mRNA translational efficiency ${ }^{(12)}$. These findings are in agreement with the specific and well-known role of

Abbreviations: 4E-BP1, 4E binding protein 1; ADQ, methionine adequate; cDNA, complementary DNA; DEF, methionine deficient; eIF2 $\alpha$, eukaryotic translation initiation factor 2 $\alpha$; EXC, methionine excess; Fbx32, F-box protein 32; INRA, Institut National de la Recherche Agronomique; LC3, microtubule-associated protein light chain 3; MuRF1, -2, -3, muscle RING finger 1, -2, -3; SQSTM1, sequestosome 1; TORC1, target of rapamycin complex 1 .

*Corresponding author: I. Seiliez, fax +335595451 52, email seiliez@st-pee.inra.fr 
methionine in mRNA translation as the primary amino acid needed to initiate protein synthesis ${ }^{(13)}$. However, there is evidence that this amino acid not only affects muscle growth as a substrate for protein synthesis but may also modulate several intracellular signalling pathways involved in the regulation of mRNA translation and the two major proteolytic pathways (ubiquitin-proteasome and autophagy-lysosomal). More precisely, methionine availability has been reported to regulate the target of rapamycin complex 1 (TORC1) signalling pathway and protein synthesis in avian QM7 myoblasts ${ }^{(14)}$ and the expression of the proteasomal gene F-box protein 32 (Fbx32, also known as atrogin-1 or $M A F b x$ ) in quail QT6 cells $^{(15)}$. Similarly, the eukaryotic translation initiation factor $2 \alpha$ /activating transcription factor 4 (eIF $2 \alpha /$ ATF 4$)$ pathway has recently been shown to direct an autophagy gene transcriptional programme in response to methionine starvation in mouse embryonic fibroblast cells ${ }^{(16)}$. This amino acid could thus act as a regulator of muscle growth in the same manner as certain hormones (e.g. insulin and insulin-like growth factor 1) in accordance with the concept of 'nutrient signal' developed over the last 10 years for amino acids such as leucine ${ }^{(17-21)}$.

Several studies have demonstrated that supplementation of methionine in diets rich in plant proteins can improve the growth response of many fish species ${ }^{(8,22,23)}$. To gain more knowledge on the influence of methionine intake on growth and nutrient accretion, several groups have investigated the effect of graded concentrations of methionine in the diet on the hepatic metabolism of fish $^{(24-29)}$. The results of our previous study on rainbow trout hepatocytes have revealed that methionine availability controls the activation of the TORC1 intracellular signalling pathway as well as the expression of several metabolism-related genes in this species ${ }^{(27)}$. These data suggest that the signalling role of methionine is well conserved between lower and higher vertebrates. However, until now, no data are available on the specific role of this amino acid in the molecular control of muscle growth in any fish species. As muscle protein synthesis rates are low in fish despite the high efficiency of protein deposition, it is considered essential to gain full insight into the protein degradation pathways ${ }^{(30)}$. The aim of the present study was to determine the effect of diets that differ in methionine concentrations on the mechanisms involved in muscle protein turnover in rainbow trout (Oncorhynchus mykiss). More specifically, we investigated the effect of dietary methionine deficiency or excess on several main factors involved in the regulation of mRNA translation and the two major muscle proteolytic pathways (ubiquitin-proteasome and autophagy-lysosomal).

\section{Materials and methods}

The present experiment was carried out in accordance with the EU legal frameworks, specifically those related to the protection of animals used for scientific purposes (i.e. Directive 2010/63/EU), and under the French legislation governing the ethical treatment of animals (Decret no. 2001-464, 29 May 2001). The investigators carrying out the experiment had 'level 1' or 'level 2' certification, bestowed by the Direction Départementale des Services Vétérinaires (French veterinary services) to carry out animal experiments (Institut National de la Recherche Agronomique (INRA) 2002-36, 14 April 2002).

\section{Feeding trial and experimental procedures}

Sexually immature rainbow trout (O. mykiss) having a mean initial weight of $40 \mathrm{~g}$ were reared in our experimental fish farm facilities (INRA, Donzacq, France) in a flow-through rearing system supplied with natural spring water $\left(17^{\circ} \mathrm{C}\right)$ under natural photoperiod during the months of DecemberJanuary. The fish were distributed into nine circular tanks (300 litres; three tanks per diet; thirty eight fish/tank). Triplicate groups of trout were fed for 6 weeks with one of the three isonitrogenous extruded diets manufactured in our experimental facilities of Donzacq, France (Table 1). The diets differed only in dietary methionine concentrations: deficient (DEF); adequate (ADQ); excess (EXC). The adequate concentration $(0.82 \mathrm{~g}$ methionine or $1.25 \mathrm{~g}$ total sulphur amino acids methionine+cysteine per $100 \mathrm{~g}$ diet) corresponds to the requirement value for rainbow trout (NRC, 2011).

Table 1. Ingredients and analytical composition of the diets

\begin{tabular}{|c|c|c|c|}
\hline & DEF & $\mathrm{ADQ}$ & EXC \\
\hline \multicolumn{4}{|l|}{ Ingredients (\%) } \\
\hline Fish protein concentrate $^{*}$ & $6 \cdot 0$ & $6 \cdot 0$ & $6 \cdot 0$ \\
\hline Soyabean protein concentrate & 30 & 30 & 30 \\
\hline Whole wheat $\ddagger$ & $8 \cdot 5$ & 8.5 & 8.5 \\
\hline Met-devoid free amino acid blend & $10 \cdot 0$ & $9 \cdot 7$ & $9 \cdot 3$ \\
\hline DL-Met§ & 0.0 & 0.3 & 0.7 \\
\hline Gelatinised starch\| & $13 \cdot 5$ & $13 \cdot 5$ & $13 \cdot 5$ \\
\hline Fish oilq & 15 & 15 & 15 \\
\hline Cellulose ${ }^{\star \star}$ & $7 \cdot 9$ & $7 \cdot 9$ & $7 \cdot 9$ \\
\hline Deoiled soya lecithin†† & $2 \cdot 0$ & $2 \cdot 0$ & $2 \cdot 0$ \\
\hline $\mathrm{CaHPO}_{4} \cdot 2 \mathrm{H}_{2} \mathrm{O}$ & $3 \cdot 0$ & $3 \cdot 0$ & $3 \cdot 0$ \\
\hline Mineral premix $\ddagger \ddagger$ & $2 \cdot 0$ & $2 \cdot 0$ & $2 \cdot 0$ \\
\hline Vitamin premix§§ & $2 \cdot 0$ & $2 \cdot 0$ & $2 \cdot 0$ \\
\hline \multicolumn{4}{|l|}{ Analytical composition (\%) } \\
\hline DM & $94 \cdot 7$ & $94 \cdot 1$ & 94.8 \\
\hline Crude protein (\% DM) & 39.5 & 39.7 & 39.7 \\
\hline Met (\% DM) & 0.56 & 0.82 & $1 \cdot 25$ \\
\hline Cys (\% DM) & 0.47 & 0.43 & 0.47 \\
\hline Lipids (\% DM) & $20 \cdot 3$ & $20 \cdot 8$ & $20 \cdot 3$ \\
\hline Energy (kJ/g DM) & $22 \cdot 7$ & 22.9 & $22 \cdot 8$ \\
\hline NFE \|\|$(\%$ DM) & $17 \cdot 4$ & $17 \cdot 7$ & $18 \cdot 1$ \\
\hline
\end{tabular}

$D E F$, methionine deficient; $A D Q$, methionine adequate; EXC, methionine excess; NFE, N-free extract.

* CPSP-90 (Sopropeche)

†Estril 75(Sopropeche).

$\ddagger$ Sudouest aliment (Pomarez)

$\S$ Evonik.

॥ Roquette.

I Sopropeche.

${ }^{\star *}$ Rettenmaier \& Sohne.

†† Louis François.

† Mineral premix ( $\mathrm{g}$ or $\mathrm{mg} / \mathrm{kg}$ diet): calcium carbonate $(40 \% \mathrm{Ca}), 2.15 \mathrm{~g}$; magnesium oxide $(60 \% \mathrm{Mg}), 1.24 \mathrm{~g}$; ferric citrate, $0.2 \mathrm{~g}$; potassium iodide $(75 \% \mathrm{I})$, $0.4 \mathrm{mg}$; zinc sulphate $(36 \% \mathrm{Zn}), 0.4 \mathrm{~g}$; copper sulphate $(25 \% \mathrm{Cu}), 0.3 \mathrm{~g}$; manganese sulphate $(33 \% \mathrm{Mn}), 0.3 \mathrm{~g}$; dibasic calcium phosphate $(20 \% \mathrm{Ca}, 18 \% \mathrm{P})$, $5 \mathrm{~g}$; cobalt sulphate, $2 \mathrm{mg}$; sodium selenite $(30 \% \mathrm{Se}), 3 \mathrm{mg} ; \mathrm{KCl}, 0.9 \mathrm{~g} ; \mathrm{NaCl}$, $0.4 \mathrm{~g}$ (UPAE, INRA).

$\S \S$ Vitamin premix $(\mu \mathrm{g}$ or $\mathrm{mg} / \mathrm{kg}$ diet): DL- $\alpha$-tocopherol acetate, $60 \mathrm{mg}$; sodium menadione bisulphate, $5 \mathrm{mg}$; retinyl acetate, $4.5 \mathrm{mg}$; DL-cholecalciferol, $375 \mu \mathrm{g}$; thiamin, $15 \mathrm{mg}$; riboflavin, $30 \mathrm{mg}$; pyridoxine, $15 \mathrm{mg}$; $\mathrm{B}_{12}, 0.05 \mathrm{mg}$; nicotinic acid, $175 \mathrm{mg}$; folic acid, $500 \mathrm{mg}$; inositol, $1000 \mathrm{mg}$; biotin, $2.5 \mathrm{mg}$; calcium pantothenate, $50 \mathrm{mg}$; choline chloride, $2000 \mathrm{mg}$ (UPAE, INRA).

||| NFE (carbohydrate): $100 \%$ (crude protein $\%$ + crude fat $\%$ + crude fibre $\%+$ moisture $\%+$ ash\%). 
The concentration of cysteine was maintained constant at $0.45 \mathrm{~g}$ cysteine per $100 \mathrm{~g}$ of diet. Each diet was distributed by hand to visual satiation (two meals/d, at 08.00-09.00 and 16.00-17.00 hours), and feed consumption was recorded per tank. To follow growth and feed utilisation, the fish were counted and group-weighed at the start and end of the experiment.

Individual body mass was calculated as the final biomass divided by the number of fish in each tank. Daily growth coefficient was calculated as $100 \times$ (mean final body mass ${ }^{1 / 3}-$ mean initial body mass $\left.^{1 / 3}\right) / d$. Daily feed intake was calculated as $100 \times$ the total amount of ingested food $(\mathrm{kg})$ divided by the mean biomass over the experimental period ((initial biomass + final biomass)/2, expressed as kg wet mass) and the number of days. Feed efficiency was estimated as the gain in total biomass ((final biomass - initial biomass) (kg wet mass)) divided by the amount of ingested DM (kg DM) (Table 2).

At the end of the feeding trial, three fish were anaesthetised with benzocaine solution $(30 \mathrm{mg} / \mathrm{l}$ water) and sampled from each tank at 4,8 and $16 \mathrm{~h}$ after feeding the last meal. The fish were killed by a sharp blow to the head. The gut content of the sampled fish was systematically checked to ensure that the fish sampled had effectively consumed the diet. A sample of laterodorsal white muscle collected from each fish was dissected, snap-frozen in liquid $\mathrm{N}_{2}$ and then stored at $-80^{\circ} \mathrm{C}$ before further mRNA and protein analyses.

\section{Chemical composition of the diets}

The chemical composition of the diets was determined as follows: (1) DM was determined after drying at $105^{\circ} \mathrm{C}$ for $24 \mathrm{~h}$; (2) protein content $(\mathrm{N}$ content $\times 6.25$ ) was determined using the Kjeldahl method after acid digestion; (3) fat content was determined by petroleum diethyl ether extraction (Soxtherm); (4) gross energy content was determined in an adiabatic bomb calorimeter (IKA). Dietary amino acid concentrations were determined after hydrolysis with $6 \mathrm{M}-\mathrm{HCl}$ for $24 \mathrm{~h}$ at $110^{\circ} \mathrm{C}$ and quantified by ion exchange chromatography with post-column derivatisation with ninhydrin ${ }^{(31)}$.

\section{Protein extraction and Western blot analyses}

The muscle samples of fish sampled at $4 \mathrm{~h}$ after feeding the last meal $(300 \mathrm{mg}$ ) were homogenised on ice using an
ULTRA-TURRAX homogeniser (IMLAB Sarl). During homogenisation, the samples were kept in $2 \mathrm{ml}$ of buffer containing $150 \mathrm{~mm}-\mathrm{NaCl}, 10 \mathrm{~mm}$-Tris, $1 \mathrm{~mm}$-ethylene glycol tetraacetic acid, 1 mm-EDTA, $100 \mathrm{~mm}$-sodium fluoride, $4 \mathrm{~mm}$-sodium pyrophosphate, 2 mm-sodium orthovanadate, $1 \%$ Triton $\mathrm{X}-100,0.5 \%$ Nonidet P-40/IGEPAL and a protease inhibitor cocktail (Roche). The homogenates were centrifuged at $1000 \mathrm{~g}$ for $15 \mathrm{~min}$ at $4^{\circ} \mathrm{C}$, and the supernatants were then centrifuged for $30 \mathrm{~min}$ at $20000 \mathrm{~g}$. The resulting supernatants ( $n 6$ per time point) were stored at $-80^{\circ} \mathrm{C}$. Protein concentrations were determined using the Bradford reagent method ${ }^{(32)}$. The muscle samples $(20 \mu \mathrm{g})$ were subjected to SDS-PAGE and Western blot analyses using the appropriate antibodies: anti-phosho S6 (Ser235/Ser236, \#4856; Cell Signaling Technologies); anti-carboxyl terminal S6 (\#2217; Cell Signaling Technologies); eIF4E (4E)-binding protein 1 (4E-BP1, Thr37/ Thr46, \#9459; Cell Signaling Technologies); anti-4E-BP1 (\#9452; Cell Signaling Technologies); anti-phospho eIF2 $\alpha$ (Ser51, \#9721; Cell Signaling Technologies); anticarboxyl terminal eIF2 $\alpha$ (\#9722; Cell Signaling Technologies); anti-microtubule-associated protein light chain 3B (LC3B, \#2775; Cell Signaling Technologies); anti-sequestosome 1 (SQSTM1, \#10117; Santa Cruz); anti-beclin 1 (\#3738; Cell Signaling Technologies); anti- $\beta$-tubulin (\#2146; Cell Signaling Technologies). All primary antibodies used have been shown to cross-react successfully with rainbow trout proteins of interest ${ }^{(33-37)}$. For beclin 1, the amino acid sequence of the corresponding protein was monitored in the SIGENAE database (http://www.sigenae.org) to check for the conservation of the antigen sequence with the corresponding sequence from mammals, ensuring a good specificity (79\%) of the mammalian antibody used in the analysis of the samples. After washing, the membranes were incubated with an IRDye IR secondary antibody (LI-COR, Inc., Biotechnology). The bands were visualised by IR fluorescence using the Odyssey ${ }^{\circledR}$ Imaging System (LI-COR, Inc.) and quantified using the Odyssey Infrared Imaging System software (version 1.2; Application Software).

\section{Analysis of mRNA levels: quantitative RT-PCR}

The analysis of mRNA levels was carried out using the white muscle samples of fish sampled at 4, 8 and $16 \mathrm{~h}$ after feeding

Table 2. Growth performance of trout fed the experimental diets for 6 weeks (Mean values with their standard errors; $n 3$ tanks per diet)

\begin{tabular}{|c|c|c|c|c|c|c|}
\hline & \multicolumn{2}{|c|}{ DEF } & \multicolumn{2}{|c|}{$A D Q$} & \multicolumn{2}{|c|}{ EXC } \\
\hline & Mean & SEM & Mean & SEM & Mean & SEM \\
\hline Initial body weight (g) & $41 \cdot 1$ & 0.6 & $41 \cdot 1$ & 0.6 & $41 \cdot 1$ & 0.6 \\
\hline Final body weight $(\mathrm{g})$ & $57 \cdot 6^{\mathrm{b}}$ & 0.8 & $73 \cdot 9^{a}$ & $3 \cdot 2$ & $78 \cdot 5^{\mathrm{a}}$ & $2 \cdot 7$ \\
\hline Daily growth index (\%/d) & $0.99^{c}$ & 0.09 & $1 \cdot 77^{\mathrm{b}}$ & 0.11 & $1.98^{\mathrm{a}}$ & 0.08 \\
\hline Feed intake (\% body weight/d) & $1 \cdot 51^{b}$ & 0.13 & $1 \cdot 65^{\mathrm{a}, \mathrm{b}}$ & 0.04 & $1.77^{\mathrm{a}}$ & 0.10 \\
\hline Feed efficiency & $0.52^{b}$ & 0.06 & $0.82^{a}$ & 0.03 & $0.84^{a}$ & 0.07 \\
\hline
\end{tabular}

$D E F$, methionine deficient; $A D Q$, methionine adequate; EXC, methionine excess.

$a, b, c$ Mean values with unlike superscript letters were significantly different among the three dietary groups $(P<0.05$; one-way ANOVA followed by the Student-Newman-Keuls multiple-comparison test). 
Table 3. Sequences of the primer pairs used in the quantitative real-time RT-PCR assays

\begin{tabular}{|c|c|c|}
\hline Genes & Forward primer & Reverse primer \\
\hline \multicolumn{3}{|c|}{ Autophagy-related genes } \\
\hline $\operatorname{atg} 121$ & 5'-GATGGAGGCCAATGAACAGC-3' & 5'-GCGTTTGAACTGAAAAGGGCTAA- $3^{\prime}$ \\
\hline atg $4 b$ & 5'-TATGCGCTTCCGAAAGTTGTC-3' & 5'-CAGGATCGTTGGGGTTCTGC-3' \\
\hline Uvrag & 5'-AGGATTTCCAAGCGAAGGAT-3' & 5'-GTTCTCCTCGAGGGTACAGG-3' \\
\hline SQSTM1 & 5'-AGCCCACTGGGTATCGATGT-3' & 5'-GGTCACGTGAGTCCATTCCT-3' \\
\hline Mul1 & 5'-CCACGAGATGGAGGAGATGT-3' & 5'-AGAGCGTTGTGGAAGCAACT-3' \\
\hline Bnip3 & 5'-CCTGTGACAGTCCTCCGAGA-3' & 5'-CCACTTCACGTCTCCGTTCT-3' \\
\hline \multicolumn{3}{|c|}{ Proteasome-related genes } \\
\hline Fbx32 & 5'-TGCGATCAAATGGATTCAAA-3' & 5'-GATTGCATCATTTCCCCACT-3' \\
\hline MuRF1 & 5'-CTGATTAGTGGCAAGGAGCTG-3' & 5'-GTAAGGTGCTCCATGTTCTCG-3' \\
\hline MuRF2 & 5'-TGGAGGAGTCAGAGATGGCTA-3' & 5'-TCCAGGTGGGAGATGTTAGTG-3' \\
\hline MuRF3 & 5'-ATGTCCATTGCAGGGACTCTA-3' & 5'-AACTGGGGTAAGCCATTGTGT-3' \\
\hline ZNF216 & 5'-AAGAGGGTGGGCCTCACAG-3' & 5'-GACATCCTTTTGCCACTCGT-3' \\
\hline Trim32 & 5'-AAAGGACAGCTGATGGTGCT-3' & 5'-GAAATCGGATCATGGAGGAA-3' \\
\hline \multicolumn{3}{|c|}{ Reference gene } \\
\hline$E F 1 \alpha$ & 5'-TCCTCTTGGTCGTTTCGCTG-3' & 5'-ACCCGAGGGACATCCTGTG-3' \\
\hline
\end{tabular}

the last meal. Total RNA was extracted using TRIzol Reagent (Invitrogen) according to the manufacturer's recommendations. Using the SuperScript III RNaseH-RT kit (Invitrogen) with random primers (Promega), $1 \mu \mathrm{g}$ of the resulting total RNA ( $n 6$ per time point) was reverse-transcribed into complementary DNA (cDNA) according to the manufacturer's instructions. Details regarding the primer sequences used in the quantitative real-time RT-PCR assays, as well as the protocol conditions of the assays, have been published previously ${ }^{(35,36,38)}$. Primers of the SQSTM1, UV radiation resistance-associated gene protein (Uvrag), Bcl-2/adenovirus E1B $19 \mathrm{kDa}$-interacting protein 3 (Bnip3), mitochondrial ubiquitin ligase activator of NF-кB 1 (Mul1), zinc finger protein 216 (ZNF216) and tripartite motifcontaining 32 (Trim32) genes were newly designed using Primer3 software, as described previously ${ }^{(38)}$. To confirm the specificity of the newly developed RT-PCR assay, the amplicon was purified and sequenced (Beckman-Coulter Genomics). The primers used in the real-time RT-PCR assays are listed in Table 3. Quantitative RT-PCR assays were carried out on the Roche LightCycler 480 System (Roche Diagnostics). The assays were carried out using a reaction mix of $6 \mu l$ per sample, each of which contained $2 \mu \mathrm{l}$ of diluted cDNA template, $0 \cdot 24 \mu \mathrm{l}$ of each primer $(10 \mu \mathrm{m}), 3 \mu \mathrm{l}$ of LightCycler 480 SYBRH Green I Master Mix and $0.52 \mu \mathrm{l}$ of DNase/RNasefree water ( 5 PRIME GmbH). The PCR protocol was initiated at $95^{\circ} \mathrm{C}$ for $10 \mathrm{~min}$ for the initial denaturation of the cDNA and the activation of the hot-start Taq-polymerase, followed by forty-five cycles of a three-step amplification programme $\left(15 \mathrm{~s}\right.$ at $95^{\circ} \mathrm{C}, 10 \mathrm{~s}$ at $60-64^{\circ} \mathrm{C}$ and $15 \mathrm{~s}$ at $72^{\circ} \mathrm{C}$ ), according to the primer set used (Table 3 ). Melting curves were systematically monitored (temperature gradient at $1 \cdot 1{ }^{\circ} \mathrm{C} / 10 \mathrm{~s}$ from 65 to $94^{\circ} \mathrm{C}$ ) at the end of the last amplification cycle to confirm the specificity of the amplification reaction. Each PCR assay included replicate samples (duplicate of reverse transcription and PCR amplification, respectively) and negative controls (RT- and cDNA template-free samples, respectively). For the expression analysis of mRNA, relative quantification of target gene expression was done using the $\Delta C_{\mathrm{T}}$ method described by Pfaffl et $a l^{(39)}$. The relative gene expression value of elongation factor $1 \alpha(E F 1 \alpha)$ was used for the normalisation of the measured expression values of the target mRNA, and it was found to not change significantly over time (data not shown). In all cases, PCR efficiency was measured by the slope of a standard curve using serial dilutions of cDNA. In all cases, PCR efficiency values ranged between $1 \cdot 8$ and $2 \cdot 2$.

\section{Statistical analyses}

Results are expressed as means with their standard errors ( $n$ 6). Statistical analyses of growth performance and protein phosphorylation were carried out using one-way ANOVA to detect significant differences. Gene expression data were analysed using two-way ANOVA. The Newman-Keuls multiplerange test was used to compare means in case of a significant effect $(P<0 \cdot 05)$.

\section{Results}

\section{Growth performance, feed intake and feed efficiency}

The feed intake of fish fed the ADQ diet was similar to that of fish fed the DEF and EXC diets, but it differed slightly between the latter two groups (Table 2). As expected, at the end of the 6-week feeding trial, the final body weight as well as the daily growth index was lower in fish fed the DEF diet than in those fed the ADQ and EXC diets (Table 2). Also, feed efficiency was higher in fish fed the ADQ and EXC diets than in those fed the DEF diet (Table 2).

\section{Muscle S6, 4E binding protein 1 and eukaryotic translation initiation factor $2 \alpha$ phosphorylation status}

We investigated the effect of feeding the three experimental diets with graded concentrations of dietary methionine on 
the phosphorylation of three translation initiation factors (S6, 4E-BP1 and eIF2 $\alpha$ ) in the muscle of trout sampled $4 \mathrm{~h}$ after feeding the last meal. As shown in Fig. 1(A), the phosphorylation of S6 in fish fed the DEF diet was significantly reduced compared with that in fish fed the EXC diet, whereas intermediate results were obtained for fish fed the ADQ diet. In contrast, the phosphorylation of 4E-BP1 was not different among the three dietary groups (Fig. 1(B)). Finally, the phosphorylation of eIF $2 \alpha$ was significantly lower in fish fed the EXC diet than in those fed the DEF diet, but it did not differ between the fish fed the ADQ diet and those fed the EXC and DEF diets (Fig. 1(C)).

\section{Levels of the muscle autophagy-related markers microtubule-associated protein light chain 3-II, sequestosome 1 and beclin 1}

We monitored the levels of LC3-II as well as those of SQSTM1 and beclin 1 in the skeletal muscle of trout fed the three experimental diets and sampled $4 \mathrm{~h}$ after feeding the last meal. To date, the detection of processed LC3-II by Western blot analysis has been the most reliable method for autophagy detection. As shown in Fig. 2(A), the ratio of LC3-II: $\beta$-tubulin reached significantly lower levels in fish fed the EXC diet compared with that in fish fed the DEF diet. In addition to LC3-II, SQSTM1 and beclin 1 can also be used as autophagy markers. There was no significant difference in the ratio of SQSTM1: $\beta$-tubulin among the dietary groups (Fig. 2(B)). Similar to the results obtained for LC3-II, the ratio of beclin 1: $\beta$-tubulin reached significantly lower levels in fish fed the EXC diet compared with that in fish fed the DEF diet (Fig. 2(C)).

mRNA levels of autophagy-related genes in the skeletal muscle of trout fed diets differing in methionine concentrations and sampled 4, 8 and $16 \mathrm{~h}$ after feeding the last meal

We monitored the expression levels of several autophagyrelated genes (autophagy-related $4 \mathrm{~b}(\operatorname{atg} 4 b)$, autophagy-related 12-like (atg12l), Uvrag, SQSTM1, Mul1 and Bnip3) in the muscle of fish fed the three experimental diets. As shown in Fig. 3, the mRNA levels of all the monitored autophagy-related genes were significantly higher in fish fed the DEF diet than in those fed the EXC diet. Intermediate results were obtained for fish fed the ADQ diet, with their mRNA levels being similar to those of fish fed the DEF and/or EXC diets according to the monitored gene. With the exception of Uvrag mRNA, exhibiting a significant increase in its levels between 8 and $16 \mathrm{~h}$ after feeding (Fig. 3(C)), no significant differences were observed among the sampling times for any of the genes studied (Fig. 3(A), (B), (D), (E) and (F)).

\section{mRNA levels of proteasomal genes in the skeletal muscle of trout fed diets differing in methionine concentration and sampled at 4, 8 and $16 \mathrm{~h}$ after feeding the last meal}

We monitored the mRNA levels of several proteasome-related genes (Fbx32, muscle RING finger 1 (MuRF1), MuRF2 and MuRF3, ZNF216 and Trim32) in the muscle of trout fed the three experimental diets. With the exception of MuRF1, the expression of which remained the same among the three dietary groups (Fig. 4(B)), the mRNA levels of all the other monitored proteasome-related genes exhibited a significant reduction in the muscle of fish fed the EXC diet compared with those of fish fed the DEF diet (Fig. 4(A) and (C)-(F)). However, the 'diet' effect on Fbx32 mRNA levels was evident only at $4 \mathrm{~h}$ after feeding, as revealed by the significant 'diet $\times$ time' interaction and post boc Newman-Keuls test (Fig. 4(A)). Similar to the results obtained for the autophagy-related genes, intermediate results were obtained for fish fed the ADQ diet, with their mRNA levels being similar to those of fish fed the DEF and/or EXC diets according to the monitored gene.

\section{Discussion}

The replacement of fishmeal with alternative protein sources remains a major thrust area of research for sustainable aquaculture and much has been accomplished in reducing
(A)

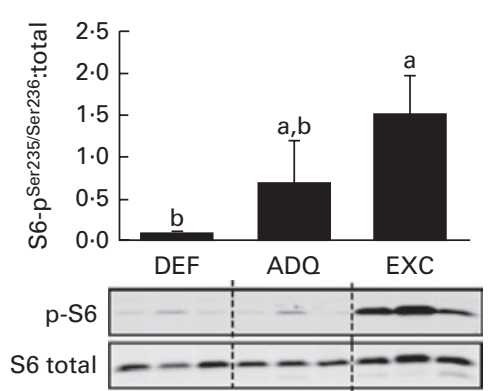

(B)

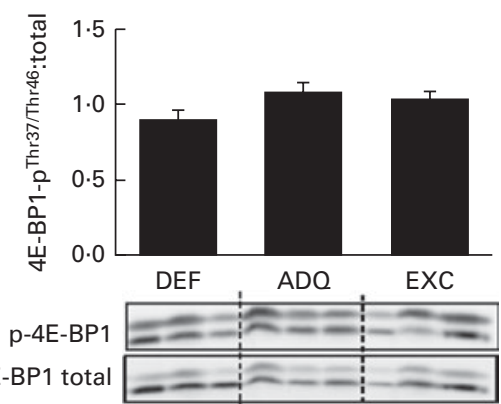

(C)

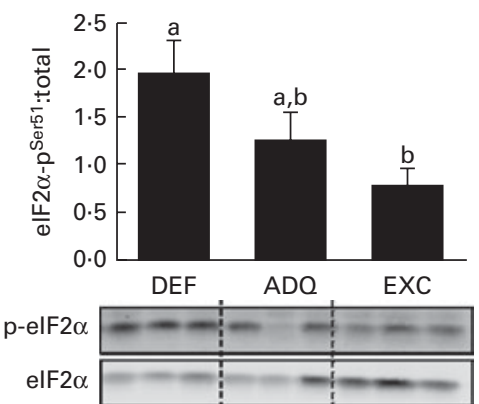

Fig. 1. Results of the Western blot analysis of (A) S6, (B) 4E binding protein 1 (4E-BP1) and (C) eukaryotic translation initiation factor $2 \alpha($ elF2 $\alpha$ ) protein phosphorylation $(p)$ in the muscle of trout fed the methionine-deficient (DEF), -adequate (ADQ) and -excess (EXC) diets and sampled $4 \mathrm{~h}$ after feeding the last meal. Total protein $(20 \mu \mathrm{g}$ per lane) was loaded on the gel. Western blot analysis was carried out on six individual samples per treatment, and a representative blot is shown. Graphs show the ratio of the amount of the phosphorylated protein:the total amount of the targeted protein. Values are means ( $n 6)$, with their standard errors represented by vertical bars. ${ }^{a, b}$ Mean values with unlike letters were significantly different among the three dietary groups $(P<0.05$; one-way ANOVA followed by the Student-Newman-Keuls multiple-comparison test). 
(A)

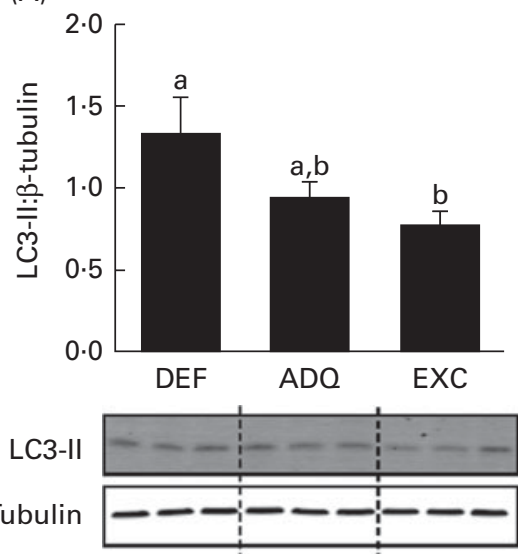

(B)

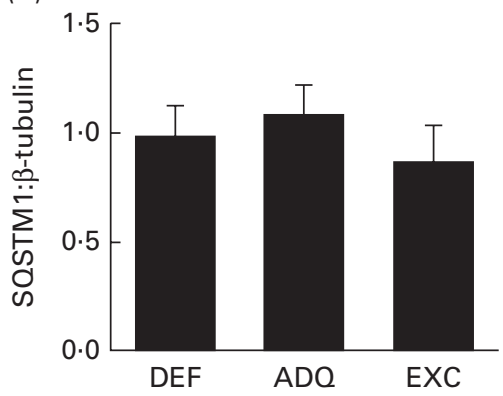

SQSTM1

$\beta$-Tubulin

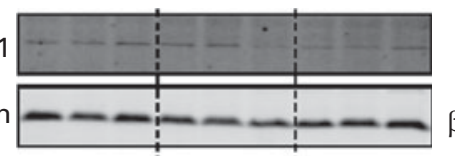

(C)

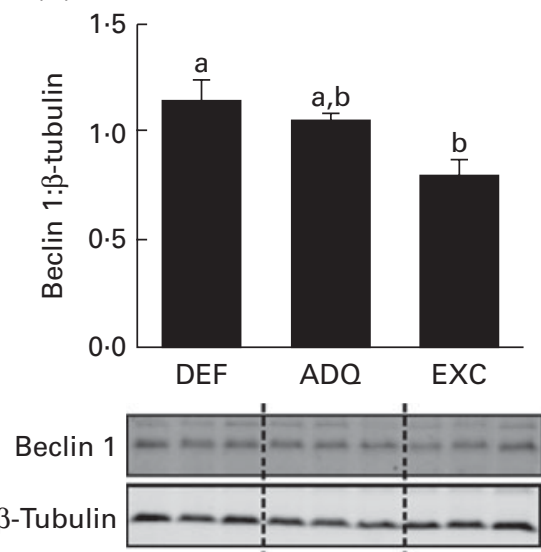

Fig. 2. Results of the Western blot analysis of (A) microtubule-associated protein light chain 3-II (LC3-II), (B) sequestosome 1 (SQSTM1) and (C) beclin 1 proteins in the muscle of trout fed the methionine-deficient (DEF), -adequate (ADQ) and -excess (EXC) diets and sampled $4 \mathrm{~h}$ after feeding the last meal. Total protein $(20 \mu \mathrm{g}$ per lane) was loaded on the gel. Western blot analysis was carried out on six individual samples per treatment, and a representative blot is shown. Graphs show the ratio of the targeted protein: $\beta$-tubulin used as a loading control. Values are means $(n 6)$, with their standard errors represented by vertical bars. ${ }^{a, b}$ Mean values with unlike letters were significantly different among the three dietary groups $(P<0.05$; one-way ANOVA followed by the Student-Newman-Keuls multiple-comparison test).

the utilisations levels of fishmeal in most species ${ }^{(40)}$. However, the use of plant protein ingredients often necessitates the addition of one or several crystalline amino acids to meet the essential amino acid requirements. Methionine is the most limiting essential amino acid in oil-seed-derived feedstuffs, such as soya-derived protein sources. Supplementation of diets containing these protein sources with synthetic methionine has been shown to optimise the nutritional value of these diets ${ }^{(8-11,41)}$, but excess dietary methionine has also been reported to affect growth performance and composition ${ }^{(42)}$. In this context, the precise determination of the molecular basis of the growth reduction induced by methionine-imbalanced diets represents an essential objective for aquaculture. In the present study, we investigated the effect of feeding diets containing different concentrations of methionine on several main factors involved in the regulation of muscle protein turnover in rainbow trout.

We found that rainbow trout fed the amino acid-imbalanced diets (DEF and EXC) did not increase their feed intake (compared with those fed the ADQ diet) to compensate for the inadequate amount of methionine supplied by this diet. At the end of the 6-week feeding trial, the final body weight as well as the feed efficiency was lower in fish fed the DEF diet than in those fed the ADQ and EXC diets. These results confirm the previously described effects of methionine availability on growth and feed utilisation in fish ${ }^{(10,24,41,43)}$ and provide a relevant design for studying the role of methionine in muscle growth-related functions in rainbow trout.

We first investigated the phosphorylation of three translation initiation factors known to play a prominent role in muscle protein synthesis, namely S6, 4E-BP1 and eIF $2 \alpha^{(44,45)}$. The results of this analysis revealed that dietary methionine concentrations could modify the phosphorylation of S6. These results are consistent with those of a previous study on avian QM7 myoblasts showing that the phosphorylation of this protein is closely related to the concentration of methionine in the culture medium ${ }^{(14)}$. According to these authors, this effect of methionine on the phosphorylation of $\mathrm{S} 6$ is mediated by the TORC1 signalling pathway, in agreement with the concept of 'nutrient signal' developed for amino acids such as leucine ${ }^{(17-21)}$. However, we failed to detect any significant change in the phosphorylation status of the TORC1 downstream effector, the 4E-BP1, between the dietary groups. Such a discrepancy between the phosphorylation levels of these two proteins ( 56 and 4E-BP1) has already been observed in the liver of rats in response to low dietary methionine intake ${ }^{(46)}$ and highlights the complexity of the signalling network involved in the regulation of the activation of these translation initiation factors. In addition, we found that the phosphorylation of eIF $2 \alpha$ was significantly induced in the muscle of trout fed the DEF diet than in the muscle of trout fed the EXC diet. This result is in line with previous findings demonstrating that growing rats fed a sulphur amino acid-deficient diet exhibit increased phosphorylation of $\mathrm{eIF} 2 \alpha$ in the liver ${ }^{(47)}$. This effect is consistent with the activation of a stress-induced $\operatorname{eIF} 2 \alpha$ kinase, presumably GCN2 (general control non-derepressible 2), in response to sulphur amino acid deprivation. However, in contrast to previous studies on the role of GCN2 and/or eIF2 $\alpha$ phosphorylation in response to amino acid deprivation ${ }^{(48)}$, the present study used diets that were limiting in, but not deficient in, methionine, an essential amino acid. Thus, the present results extend the observations to the situation in which the diet is only deficient in one essential amino acid (i.e. methionine), to an amino acid pattern that is more representative of that in diets consumed by humans and animals, and to a diet that supports growth. Overall, our results showed that rainbow trout respond to a methionine-deficient diet by affecting the phosphorylation of two main translation initiation factors (S6 and eIF2 $\alpha$ ) in the skeletal white muscle, probably leading to reduced growth and feed utilisation.

As muscle growth is determined by the balance between the rate of protein synthesis and that of protein degradation, 
(A)

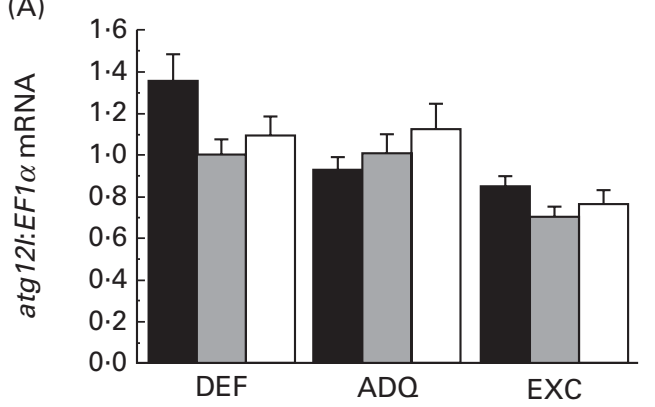

(C)

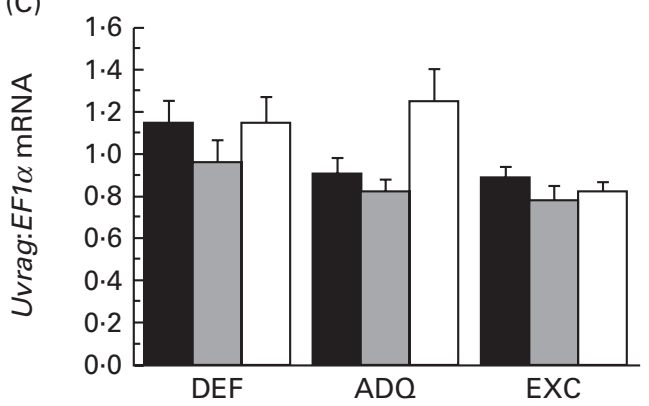

(E)

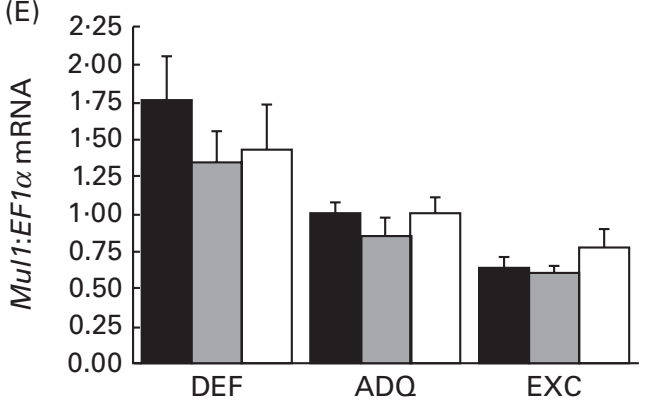

(B)

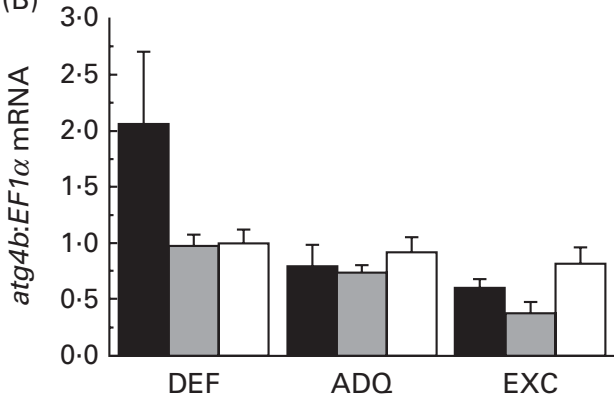

(D)

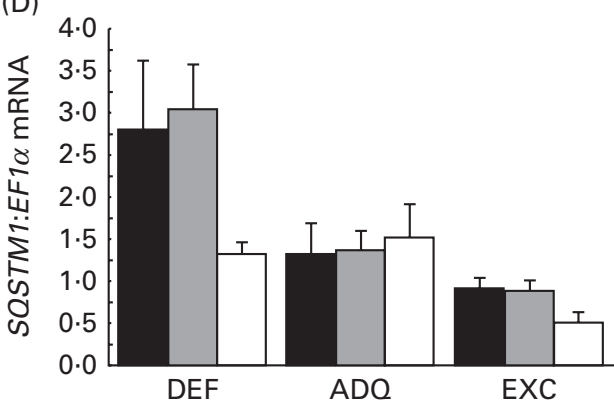

(F)

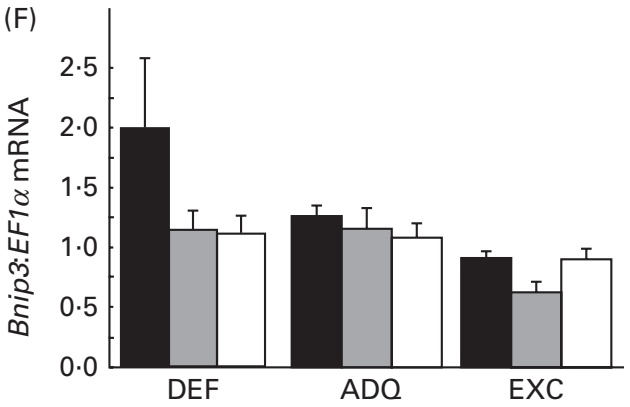

Fig. 3. Autophagy-related gene expression in the muscle of trout fed the methionine-deficient (DEF), -adequate (ADQ) and -excess (EXC) diets and sampled $4 \mathrm{~h}$ $(\square), 8 \mathrm{~h}(\square)$ and $16 \mathrm{~h}(\square)$ after feeding the last meal. The mRNA levels of (A) autophagy-related 12-like (atg12 I), (B) autophagy-related 4b (atg4b), (C) UV radiation resistance-associated gene protein (Uvrag), (D) sequestosome 1 (SQSTM1), (E) mitochondrial E3 ubiquitin protein ligase 1 (Mul1) and (F) Bcl-2/adenovirus E1B $19 \mathrm{kDa}$-interacting protein 3 (Bnip3) were measured using quantitative real-time RT-PCR assays. Expression values were normalised to those of the elongation factor $1 \alpha(E F 1 \alpha)$ transcripts. Values are means $(n 6)$, with their standard errors represented by vertical bars. A significant diet effect was observed for atg12I mRNA $(P<0.001 ; D E F=A D Q>E X C)$, atg4b mRNA $(P=0.003 ; \quad D E F>A D Q=E X C), \quad S Q S T M 1$ mRNA $(P<0.0001 ; D E F>A D Q=E X C), \quad M u l 1$ mRNA $(P<0.0001 ; \mathrm{DEF}>\mathrm{ADQ}=\mathrm{EXC})$ and Bnip3 mRNA $(P=0.0039 ; \mathrm{DEF}=\mathrm{ADQ} ; \mathrm{ADQ}=\mathrm{EXC} ; \mathrm{DEF}>\mathrm{EXC})$ (two-way ANOVA). Significant effects of diet $(P=0.005$; $\mathrm{DEF}=\mathrm{ADQ} ; \mathrm{ADQ}=\mathrm{EXC} ; \mathrm{DEF}>\mathrm{EXC})$ and time $(P=0.018 ; 4 \mathrm{~h}=8 \mathrm{~h} ; 4 \mathrm{~h}=16 \mathrm{~h} ; 16 \mathrm{~h}>18 \mathrm{~h})$ were observed for Uvrag mRNA (two-way ANOVA).

we also attempted to address the question whether dietary methionine concentrations affect the key components of proteolysis in the muscle of trout. The ubiquitin-proteasome and autophagy-lysosomal pathways are the two major intracellular proteolytic pathways in the skeletal muscle of vertebrates $^{(49)}$. Macroautophagy (hereafter referred to as autophagy) functions as an important catabolic mechanism by mediating the turnover of intracellular organelles and protein complexes through a lysosome-dependent degradative pathway ${ }^{(50,51)}$. In mammals, two main mechanisms have been identified for the induction of autophagy under stress conditions. The first is a rapid and transient transcription-independent induction mediated by TORC1 and AMP-activated protein kinase complexes ${ }^{(52)}$. During this induction, LC3B is converted from a slower-migrating unconjugated form (LC3-I) to a faster-migrating lipid-conjugated form (LC3-II) ${ }^{(53,54)}$. Our previous findings have revealed that the composition of macronutrients (protein:carbohydrate ratio) affects the feeding-mediated short-term inhibition of autophagy in the muscle of rainbow trout ${ }^{(33)}$. More precisely, we demonstrated that LC3-II levels in the muscle of rainbow trout are inhibited by re-feeding only when the proportion of dietary proteins increased at the expense of carbohydrates. In the present study, the levels of LC3-II as well as those of beclin 1 (another essential factor in autophagy interactome) were significantly increased by methionine deficiency in the diet, indicating that the formation of autophagosomes is affected not only by the protein:carbohydrate ratio in the diet but also by the profile of amino acids in the protein fraction. The autophagy-inhibitory effect of amino acids (especially leucine) has been well established in cell-culture experiments ${ }^{(16,55,56)}$. However, to our knowledge, no findings have been published to date on the in vivo effects of dietary deficiency of an essential amino acid on this degradative system. 
(A)

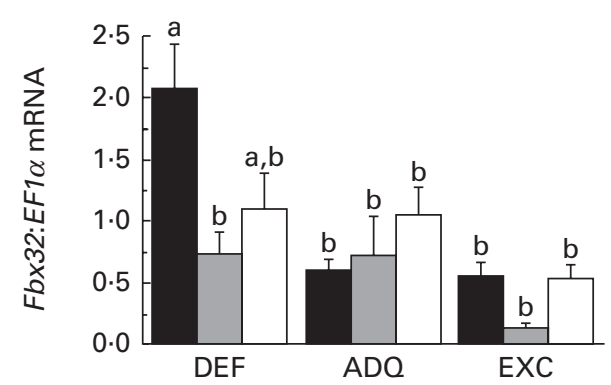

(C) 2.25

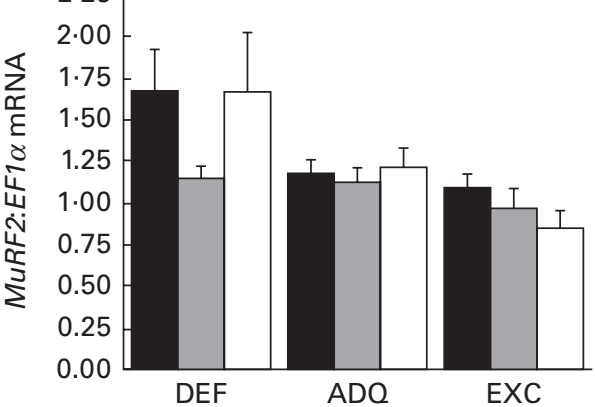

(E)

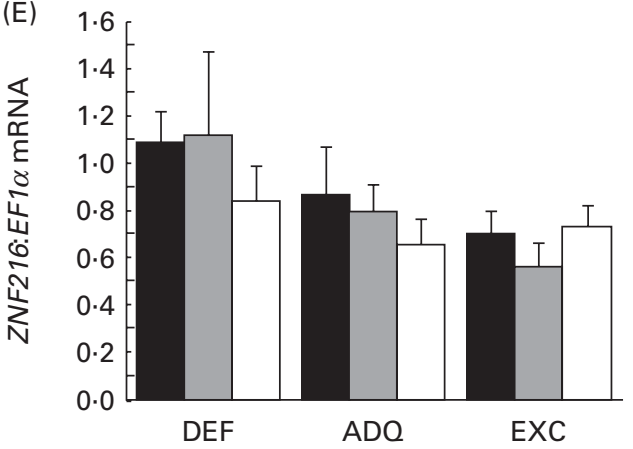

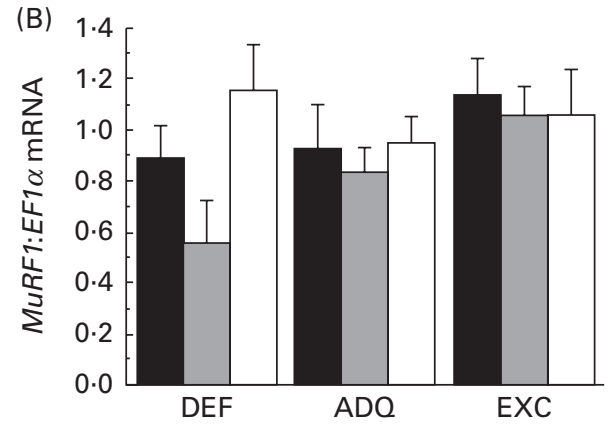

(D) 1.8

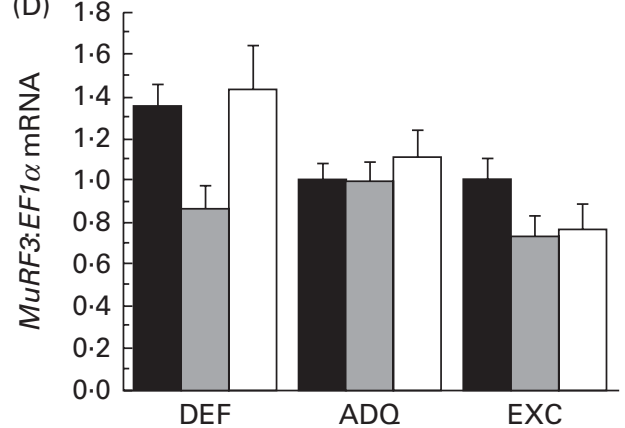

$(\mathrm{F})$

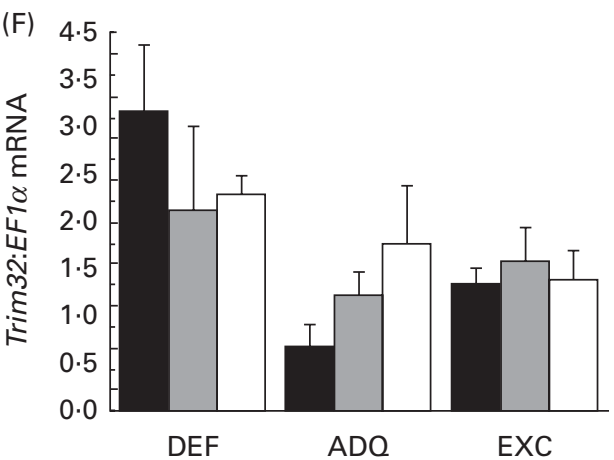

Fig. 4. Proteasomal gene expression in the muscle of rainbow trout fed the methionine-deficient (DEF), -adequate (ADQ) and -excess (EXC) diets and sampled $4 \mathrm{~h}(\square), 8 \mathrm{~h}(\square)$ and $16 \mathrm{~h}(\square)$ after feeding the last meal. The mRNA levels of (A) Fbx protein 32 (Fbx32), (B-D) the three muscle-specific RING finger 1 genes (MuRF1, MuRF2 and MuRF3, respectively), (E) zinc finger protein 216 (ZNF216) and (F) tripartite motif-containing protein 32 (Trim32) were measured using quantitative real-time RT-PCR assays. Expression values were normalised to those of the elongation factor $1 \alpha(E F 1 \alpha)$ transcripts. Values are means $(n 6)$, with their standard errors represented by vertical bars. ${ }^{a, b}$ Mean values with unlike letters were significantly different among the three dietary groups $(P<0.05$; two-way ANOVA followed by the Student-Newman-Keuls multiple-comparison test). For $F b x 32 \mathrm{mRNA}$, significant effects of diet $(P=0.0097$; DEF $>$ ADQ $=\mathrm{EXC})$ and time $\left(P=2.947 \times 10^{-5} ; 4 \mathrm{~h}>8 \mathrm{~h}=16 \mathrm{~h}\right)$ were observed and the diet $\times$ time interaction was significant $(P=0.0073)$. A significant diet effect was observed for MuRF2 mRNA $(P=0.0019 ; \mathrm{DEF}>\mathrm{ADQ}=\mathrm{EXC})$, ZNF216 mRNA $(P=0.0446 ; \mathrm{DEF}=\mathrm{ADQ} ; \mathrm{ADQ}=\mathrm{EXC} ; \mathrm{DEF}>\mathrm{EXC})$ and Trim32 mRNA $(P=0.004 ; \mathrm{DEF}>$ $\mathrm{ADQ}=\mathrm{EXC})$. Significant effects of diet $(P=0.0013$; DEF $=\mathrm{ADQ}>\mathrm{EXC})$ and time $(P=0.0216 ; 4 \mathrm{~h}=16 \mathrm{~h}>8 \mathrm{~h})$ were observed for $M u R F 3 \mathrm{mRNA}$.

The second regulatory mechanism of autophagy induction is a slower one requiring gene expression ${ }^{(57,58)}$. In the present study, we found that the mRNA levels of all the monitored autophagy-related genes were significantly higher in fish fed the DEF diet than in those fed the EXC diet. This result is consistent with our previous findings showing that amino acid availability regulates the expression of several autophagyrelated genes in trout myocytes ${ }^{(36)}$. Similarly, a recent study on mouse embryonic fibroblast cells has reported the upregulation of a large number of autophagy genes in response to leucine starvation and identified the GCN2/eIF $2 \alpha$ pathway as a central regulator of this effect ${ }^{(16)}$. Interestingly, the present results reveal that even in vivo the deficiency of methionine in the diet is also associated with an increase in eIF $2 \alpha$ phosphorylation, making possible the involvement of this signalling pathway in the observed induction of autophagyrelated genes in fish fed the DEF diet. Collectively, the present results reveal that the deficiency of methionine in the diet leads not only to the induction of the formation of autophagosomes in the muscle (revealed by LC3-II levels) but also to the increase of the mRNA levels of several autophagy genes. At physiological levels, such an induction of the expression of these genes in prolonged stress conditions has been reported to be critical to replenish key autophagy-related proteins that are destroyed during prolonged activation of autophagy ${ }^{(49)}$.

The ubiquitin-proteasome pathway is another important proteolytic pathway that has long been considered to be the primary pathway involved in muscle atrophy ${ }^{(59-62)}$. 
Protein degradation through this pathway relies on the selective attachment of ubiquitin molecules to the protein substrate by E3 ubiquitin protein ligases. Following polyubiquitination, the targeted proteins are recognised and degraded by the $26 \mathrm{~S}$ proteasome. Among the genes encoding the E3 ubiquitin ligases, Fbx32 and MuRF1 have been studied in depth and shown to play a key role in the control of skeletal muscle mass ${ }^{(63)}$. These genes are both muscle specific and upregulated during muscle atrophy ${ }^{(64,65)}$. In the present study, the mRNA levels of Fbx32 as well as those of two MuRF paralogues (MURF2 and MuRF3) were significantly higher in the muscle of trout fed the DEF diet than in that of fish fed the EXC diet. These findings are in agreement with the results of a previous study on avian QT6 cells, showing that methionine availability controls the levels of $F b \times 32$ mRNA through a TORC1-dependent mechanism ${ }^{(15)}$. In contrast, we failed to detect any difference in the mRNA levels of MuRF1 between the dietary groups, in accordance with the results of previous studies indicating differences in the in vivo regulation of Fbx32 and MuRF1 expression ${ }^{(66,67)}$. Recently, additional proteins involved in muscle protein ubiquitination and proteasome-dependent breakdown have been identified ${ }^{(68)}$. A recent paper has reported that Trim32 is a crucial E3 ligase for the degradation of thin filaments (actin, tropomyosin and troponins), $\alpha$-actinin and desmin ${ }^{(69)}$. ZNF216 has also been identified as an important player in the recognition and delivery of ubiquitinated proteins to the proteasome during muscle atrophy ${ }^{(70)}$. In the present study, the expression of these two genes was significantly induced when fish were fed the DEF diet. To our knowledge, the present study is the first to provide evidence that the amino acid composition of the diet can modulate the expression of these two genes. Overall, the present results reveal that methionine deficiency induces the expression of major factors involved in the different steps of ubiquitin-proteasome degradation, from the attachment of ubiquitin molecules to the protein substrate to the recognition and delivery of the ubiquitinated proteins to the proteasome.

In conclusion, we demonstrated that feeding rainbow trout with a diet deficient in methionine for 6 weeks results in the suppression of growth performance and affects the activation and/ or expression of several key factors involved in muscle growth. More precisely, methionine deficiency affects the phosphorylation of the two main translation initiation factors 56 and eIF $2 \alpha$ and induces the expression of several factors involved in the two major muscle proteolytic pathways (ubiquitinproteasome and autophagy-lysosomal). Whether such changes in the expression and/or activation of these growth-related factors are induced by methionine limitation is unknown, as these changes may be a direct effect of a deficiency of an essential amino acid or an indirect effect of metabolic and or/ hormonal changes induced by such a deficiency. Our findings provide the first-ever evidence of the involvement of dietary methionine in mechanisms regulating the muscle growth of fish under physiological conditions. From a practical aquaculture point of view, the present study provides valuable information on biomarkers associated with muscle growth and sulphur amino acid deficiency, a situation not uncommon in fish fed diets rich in plant-based ingredients.

\section{Acknowledgements}

The authors thank Evonik-Degussa Laboratory for the analysis of the amino acid composition of the diets. They also cordially thank C. Biran and C. Prochasson from the INRA for their technical assistance as well as the technical staff at the fish farm (F. Vallée, F. Terrier, A. Lanuque and F. Sandres).

The present study was supported by the European Union 7 th Framework project (Project Call Identifier: FP7-KBBE2011-5, Project no.: 288925, Advanced Research Initiatives for Nutrition \& Aquaculture (ARRAINA)). The ARRAINA European project also provided a fellowship to I. B.

The authors' contributions are as follows: I. B., S. S.-C., I. G., S. K., S. P. and I. S. designed the study; I. B., K. D. and A. S. conducted the study; I. B., S. S.-C., I. G., S. P. and I. S. analysed the data; I. B. S. P. and I. S. wrote the article; I. S. had primary responsibility for the final content. All authors read and approved the final manuscript.

None of the authors has any conflicts of interest to declare.

\section{References}

1. FAO (2012) The State of World Fisheries and Aquaculture. Rome: FAO.

2. Cowey CB (1995) Protein and amino acid requirements: a critique of methods. J Appl Ichthyol 11, 199-204.

3. Naylor RL, Hardy RW, Bureau DP, et al. (2009) Feeding aquaculture in an era of finite resources. Proc Natl Acad Sci US A 106, 15103-15110.

4. Carter CG \& Hauler RC (2000) Fish meal replacement by plant meals in extruded feeds for Atlantic salmon, Salmo salar L. Aquaculture 185, 299-311.

5. Kaushik SJ, Cravedi JP, Lalles JP, et al. (1995) Partial or total replacement of fish meal by soybean protein on growth, protein utilization, potential estrogenic or antigenic effects, cholesterolemia and flesh quality in rainbow trout, Oncorbynchus mykiss. Aquaculture 133, 257-274.

6. Kaushik SJ (2008) Soybean products in salmonid diets. In Alternative Protein Sources in Aquaculture Diets, pp. 261-279 [C Lim, C Webster and C-S Lee, editors] New York, NY: The Haworth Press.

7. Gatlin DM, Barrows FT, Brown P, et al. (2007) Expanding the utilization of sustainable plant products in aquafeeds: a review. Aquac Res 38, 551-579.

8. Rodehutscord M, Jacobs S, Pack M, et al. (1995) Response of rainbow trout (Oncorbynchus mykiss) growing from 50 to $150 \mathrm{~g}$ to supplements of DL-methionine in a semipurified diet containing low or high levels of cystine. J Nutr 125, 964-969.

9. Pack M, Rodehutscord M, Jacobs S, et al. (1995) Amino acid requirements of rainbow trout (Oncorbynchus mykiss) II. Protein deposition as function of dietary methionine, threonine and arginine. J Appl Ichthyol 11, 390-393.

10. Rumsey GL, Page JW \& Scott ML (1983) Methionine and cystine requirements of rainbow trout. Prog Fish Cult 45, 139-143.

11. Sveier H, Nordås H, Berge GE, et al. (2001) Dietary inclusion of crystalline D- and L-methionine: effects on growth, feed and protein utilization, and digestibility in small and large Atlantic salmon (Salmo salar L.). Aquac Nutr 7, 169-181.

12. Kino K \& Okumura J (1986) Improvement of body weight and nitrogen balance of chicks fed histidine-free or lysinefree diets with supplementation of graded levels of sulfurcontaining amino acids. Poult Sci 65, 1736-1740.

13. Bradshaw RA, Brickey WW \& Walker KW (1998) N-Terminal processing: the methionine aminopeptidase and N $\alpha$-acetyl transferase families. Trends Biochem Sci 23, 263-267. 
14. Métayer-Coustard S, Mameri H, Seiliez I, et al. (2010) Methionine deprivation regulates the S6K1 pathway and protein synthesis in avian QM7 myoblasts without activating the GCN2/eIF2 alpha cascade. J Nutr 140, 1539-1545.

15. Tesseraud S, Métayer-Coustard S, Boussaid S, et al. (2007) Insulin and amino acid availability regulate atrogin-1 in avian QT6 cells. Biochem Biophys Res Commun 357, 181-186.

16. B'chir W, Maurin A-C, Carraro V, et al. (2013) The eIF2 $\alpha$ / ATF4 pathway is essential for stress-induced autophagy gene expression. Nucleic Acids Res 41, 7683-7699.

17. Anthony JC, Yoshizawa F, Anthony TG, et al. (2000) Leucine stimulates translation initiation in skeletal muscle of postabsorptive rats via a rapamycin-sensitive pathway. J Nutr 130, 2413-2419.

18. Dardevet D, Rieu I, Fafournoux P, et al. (2003) Leucine: a key amino acid in ageing-associated sarcopenia? Nutr Res Rev 16, 61-70.

19. Kimball SR \& Jefferson LS (2004) Regulation of global and specific mRNA translation by oral administration of branched-chain amino acids. Biochem Biophys Res Commun 313, 423-427.

20. Kimball SR \& Jefferson LS (2006) Signaling pathways and molecular mechanisms through which branched-chain amino acids mediate translational control of protein synthesis. J Nutr 136, 227S-231S.

21. Yoshizawa F (2004) Regulation of protein synthesis by branched-chain amino acids in vivo. Biochem Biophys Res Commun 313, 417-422.

22. Takagi S, Shimeno S, Hosokawa H, et al. (2001) Effect of lysine and methionine supplementation to a soy protein concentrate diet for red sea bream Pagrus major. Fisheries Sci 67, 1088-1096.

23. Gaylord TG \& Barrows FT (2009) Multiple amino acid supplementations to reduce dietary protein in plant-based rainbow trout, Oncorbynchus mykiss, feeds. Aquaculture 287, 180-184.

24. Cowey CB, Cho CY, Sivak JG, et al. (1992) Methionine intake in rainbow trout (Oncorbynchus mykiss), relationship to cataract formation and the metabolism of methionine. $J$ Nutr 122, 1154-1163.

25. Walton MJ, Cowey CB \& Adron JW (1982) Methionine metabolism in rainbow trout fed diets of differing methionine and cystine content. $J$ Nutr 112, 1525-1535.

26. Espe M, Hevrøy EM, Liaset B, et al. (2008) Methionine intake affect hepatic sulphur metabolism in Atlantic salmon, Salmo salar. Aquaculture 274, 132-141.

27. Lansard M, Panserat S, Plagnes-Juan E, et al. (2011) L-Leucine, L-methionine, and L-lysine are involved in the regulation of intermediary metabolism-related gene expression in rainbow trout hepatocytes. J Nutr 141, 75-80.

28. Craig PM, Massarsky A \& Moon TW (2013) Understanding glucose uptake during methionine deprivation in incubated rainbow trout (Oncorbynchus mykiss) hepatocytes using a non-radioactive method. Comp Biochem Physiol B Biochem Mol Biol 166, 23-29.

29. Craig PM \& Moon TW (2013) Methionine restriction affects the phenotypic and transcriptional response of rainbow trout (Oncorbynchus mykiss) to carbohydrate-enriched diets. Br J Nutr 109, 402-412.

30. Kaushik SJ \& Seiliez I (2010) Protein and amino acid nutrition and metabolism in fish: current knowledge and future needs. Aquac Res 41, 322-332.

31. Llames CR \& Fontaine J (1994) Determination of amino acids in feeds: collaborative study. J Assoc Off Anal Chem 77, 1362-1402.

32. Bradford MM (1976) A rapid and sensitive method for the quantitation of microgram quantities of protein utilizing the principle of protein-dye binding. Anal Biochem 72, 248-254.
33. Belghit I, Panserat S, Sadoul B, et al. (2013) Macronutrient composition of the diet affects the feeding-mediated down regulation of autophagy in muscle of rainbow trout (O. mykiss). PLOS ONE 8, e74308.

34. Dai W, Panserat S, Mennigen JA, et al. (2013) Post-prandial regulation of hepatic glucokinase and lipogenesis requires the activation of TORC1 signalling in rainbow trout (Oncorbynchus mykiss). J Exp Biol 216, 4483-4492.

35. Seiliez I, Panserat S, Lansard M, et al. (2011) Dietary carbohydrate-to-protein ratio affects TOR signaling and metabolism-related gene expression in the liver and muscle of rainbow trout after a single meal. Am J Physiol Regul Integr Comp Physiol 300, R733-R743.

36. Seiliez I, Gabillard J-C, Riflade M, et al. (2012) Amino acids downregulate the expression of several autophagy-related genes in rainbow trout myoblasts. Autophagy 8, 364-375.

37. Seiliez I, Taty Taty GC, Bugeon J, et al. (2013) Myostatin induces atrophy of trout myotubes through inhibiting the TORC1 signaling and promoting ubiquitin-proteasome and autophagy-lysosome degradative pathways. Gen Comp Endocrinol 186, 9-15.

38. Seiliez I, Gutierrez J, Salmerón C, et al. (2010) An in vivo and in vitro assessment of autophagy-related gene expression in muscle of rainbow trout (Oncorbynchus mykiss). Comp Biochem Physiol B Biochem Mol Biol 157, 258-266.

39. Pfaffl MW, Horgan GW \& Dempfle L (2002) Relative expression software tool $\left(\right.$ REST $^{\mathcal{C}}$ ) for group-wise comparison and statistical analysis of relative expression results in real-time PCR. Nucleic Acids Res 30, e36.

40. Lim C, Webster CD \& Lee C-S (2008) Alternative Protein Sources in Aquaculture Diets, 571 pp. New York, NY: The Haworth Press.

41. Mambrini M, Roem AJ, Carvèdi JP, et al. (1999) Effects of replacing fish meal with soy protein concentrate and of DL-methionine supplementation in high-energy, extruded diets on the growth and nutrient utilization of rainbow trout, Oncorbynchus mykiss. J Anim Sci 77, 2990-2999.

42. Jackson AJ \& Capper BS (1982) Investigations into the requirements of the tilapia Sarotherodon mossambicus for dietary methionine, lysine and arginine in semi-synthetic diets. Aquaculture 29, 289-297.

43. Kim K-I, Kayes TB \& Amundson CH (1992) Requirements for sulfur amino acids and utilization of D-methionine by rainbow trout (Oncorbynchus mykiss). Aquaculture 101, 95-103.

44. Kimball SR, Shantz LM, Horetsky RL, et al. (1999) Leucine regulates translation of specific mRNAs in $\mathrm{L} 6$ myoblasts through mTOR-mediated changes in availability of eIF4E and phosphorylation of ribosomal protein S6. $\mathrm{J}$ Biol Chem 274, 11647-11652.

45. Kimball SR \& Jefferson LS (2002) Control of protein synthesis by amino acid availability. Curr Opin Clin Nutr 5, 63-67.

46. Sikalidis AK, Mazor KM, Kang M, et al. (2013) Total 4EBP1 is elevated in liver of rats in response to low sulfur amino acid intake. J Amino Acids 2013, 864757.

47. Sikalidis AK \& Stipanuk MH (2010) Growing rats respond to a sulfur amino acid-deficient diet by phosphorylation of the $\alpha$ subunit of eukaryotic initiation factor 2 heterotrimeric complex and induction of adaptive components of the integrated stress response. J Nutr 140, 1080-1085.

48. Anthony TG, McDaniel BJ, Byerley RL, et al. (2004) Preservation of liver protein synthesis during dietary leucine deprivation occurs at the expense of skeletal muscle mass in mice deleted for eIF2 kinase GCN2. J Biol Chem 279, 36553-36561.

49. Sandri M (2010) Autophagy in skeletal muscle. FEBS Lett 584, 1411-1416. 
50. Chen Y \& Klionsky DJ (2011) The regulation of autophagy unanswered questions. J Cell Sci 124, 161-170.

51. Cuervo A (2004) Autophagy: many paths to the same end. Mol Cell Biochem 263, 55-72.

52. Kim J, Kundu M, Viollet B, et al. (2011) AMPK and mTOR regulate autophagy through direct phosphorylation of Ulk1. Nat Cell Biol 13, 132-141.

53. Mizushima N \& Yoshimori T (2007) How to interpret LC3 immunoblotting. Autophagy 3, 542-545.

54. Klionsky DJ, Abdalla F, Abeliovich H, et al. (2012) Guidelines for the use and interpretation of assays for monitoring autophagy. Autophagy 8, 445-554.

55. Mordier S, Deval C, Béchet D, et al. (2000) Leucine limitation induces autophagy and activation of lysosome-dependent proteolysis in $\mathrm{C} 2 \mathrm{C} 12$ myotubes through a mammalian target of rapamycin-independent signaling pathway. J Biol Chem 275, 29900-29906.

56. Lorin S, Tol MJ, Bauvy C, et al. (2013) Glutamate dehydrogenase contributes to leucine sensing in the regulation of autophagy. Autophagy 9, 850-860.

57. Mammucari C, Milan G, Romanello V, et al. (2007) FoxO3 controls autophagy in skeletal muscle in vivo. Cell Metab 6, 458-471.

58. Füllgrabe J, Klionsky DJ \& Joseph B (2013) Histone posttranslational modifications regulate autophagy flux and outcome. Autophagy 9, 1621-1623.

59. Attaix D \& Taillandier D (1998) The critical role of the ubiquitin-proteasome pathway in muscle wasting in comparison to lysosomal and $\mathrm{Ca}^{2+}$-dependent systems. In Advances in Molecular and Cell Biology, pp. 235-266 [EE Bittar and AJ Rivett, editors]. Stamford, CT: JAI Press.

60. Lecker SH, Solomon V, Mitch WE, et al. (1999) Muscle protein breakdown and the critical role of the ubiquitin- proteasome pathway in normal and disease states. $J$ Nutr 129, 227S-237S.

61. Lecker SH, Jagoe RT, Gilbert A, et al. (2004) Multiple types of skeletal muscle atrophy involve a common program of changes in gene expression. FASEB J 18, 39-51.

62. Kumamoto T, Fujimoto S, Ito T, et al. (2000) Proteasome expression in the skeletal muscles of patients with muscular dystrophy. Acta Neuropathol (Berl) 100, 595-602.

63. Glass DJ (2010) Signaling pathways perturbing muscle mass. Curr Opin Clin Nutr 13, 225-229.

64. Bonaldo P \& Sandri M (2013) Cellular and molecular mechanisms of muscle atrophy. Dis Model Mech 6, 25-39.

65. Schiaffino S, Dyar KA, Ciciliot S, et al. (2013) Mechanisms regulating skeletal muscle growth and atrophy. FEBS J $\mathbf{2 8 0}$, 4294-4314.

66. Tesseraud S, Bouvarel I, Collin A, et al. (2009) Daily variations in dietary lysine content alter the expression of genes related to proteolysis in chicken pectoralis major muscle. J Nutr 139, 38-43.

67. Frost RA, Nystrom GJ, Jefferson LS, et al. (2007) Hormone, cytokine, and nutritional regulation of sepsis-induced increases in atrogin-1 and MuRF1 in skeletal muscle. Am $J$ Physiol Endocrinol Metab 292, E501-E512.

68. Sandri M (2013) Protein breakdown in muscle wasting: role of autophagy-lysosome and ubiquitin-proteasome. Int J Biochem Cell Biol 45, 2121-2129.

69. Cohen S, Zhai B, Gygi SP, et al. (2012) Ubiquitylation by Trim32 causes coupled loss of desmin, Z-bands, and thin filaments in muscle atrophy. J Cell Biol 198, 575-589.

70. Hishiya A, Iemura S, Natsume T, et al. (2006) A novel ubiquitin-binding protein ZNF216 functioning in muscle atrophy. EMBO J 25, 554-564. 